\title{
Going beyond the text: Turning classrooms into communities of practice to uncover and create noncanonical knowledge
}

\author{
Darin Freeburg \\ School of Library and Information Science, University of South Carolina, Columbia, SC, USA \\ E-mail: darinf@mailbox.sc.edu
}

\begin{abstract}
Every discipline has an existing canon - seen in textbooks, scholarly journals, conference proceedings, etc. - that explicitly outlines existing practice and thought. Recognizing the inadequacy of these canons, the current paper outlines an approach to classroom instruction that helps students move beyond these texts as they create and discover noncanonical knowledge. This noncanonical approach focuses on turning classrooms into Communities of Practice (CoP). There is myriad literature on the utility of such groups for knowledge creation and learning in organizations, yet this paper is unique in introducing it to classroom instruction. By turning classrooms into an adapted $\mathrm{CoP}$, instructors are situated to move beyond the texts or canons of their disciplines. This occurs as they a) invite unique student contributions to create ideas and knowledge that go beyond existing texts, b) develop trust and community among students that goes beyond simple icebreakers and standard group work, and c) engage consistently in action that recognizes the practical utility of what is learned. This is essential to any discipline, yet it has a special place in the field of Library and Information Science (LIS) which - long a discipline of the text - is itself moving outside of this as it focuses on knowledge creation [1]. In addition to its theoretical foundation, the paper provides practical steps instructors can take to turn their classrooms into CoPs that move beyond the existing text.
\end{abstract}

Keywords: Communities of practice, LIS pedagogy, knowledge creation, knowledge management

\section{Introduction}

This paper outlines a noncanonical approach to education within information, adapting Communities of Practice (CoP) to achieve its stated goals. It is focused on the creation of noncanonical knowledge, which includes the workarounds and new ideas that may conflict with or extend the existing information about a given subject area or discipline. The existing explicit texts for any discipline - seen in the typical classroom - are insufficient. Orr wrote about Xerox workers who would carry large service manuals around with them to diagnose machine issues [2]. The central problem with this was that, often, the solution to a problem was not in these manuals. The manual could not keep up with the discovery of new problems. The diagnosis of a machine - instead - was a narrative process involving "the circulation of stories among the community of technicians [as] the principal means by which the technicians stay informed of the developing subtleties of machine behavior in the field" [2, p. 2]. Brown and Duguid [3] referred to these technical manuals as 
the canonical knowledge in a given area, while the workarounds that come out of social interaction represent noncanonical knowledge. This is the goal of education as outlined in this paper.

Every discipline has an existing canon or text - seen in textbooks, scholarly journals, conference proceedings, etc. - that explicitly outlines existing practice and thought. The word, texts, in the current paper is used to signify any existing explicit documentation about a subject. It is used interchangeably with the word, canon. It is also similar to Kuhn's paradigms [4]. These canons, texts, or paradigms are theoretical rather than empirical, suggesting that they are biased, fallible, and subject to change. Yet, they are often held in spite of counter-evidence so that science can continue to advance. As things change and progress, there is a growing sense that "an existing paradigm has ceased to function adequately in the exploration of an aspect of nature to which that paradigm itself had previously led the way" [4, p. 92]. These are the moments of scientific revolution and paradigm shifts. While continuing in the spirit of changing canons, texts, and paradigms, a noncanonical approach shifts the locus of this change. Rather than have these revolutions "restricted to a narrow subdivision of the scientific community" [4, p. 92] - waiting until they "[capture] the hearts and minds of the commanding figures" [5, p. 72] - a noncanonical approach sees students as the catalyst for bottom-up change. As they bring in their own expertise and experiences, students question the existing canons and bring about revolutions of thought that fundamentally alter practice. This is likely to be met with resistance by instructors who feel that certain elements of their disciplines are fundamental, and who question the role of student amateurs in questioning these elements. This is not to suggest that these instructors are incorrect to hold certain things as fundamental, e.g. the spherical-like shape of the earth is fundamental to astronomy. However, it is a risk that instructors must take if they agree that noncanonical knowledge creation is one of the goals of education. The space for this is created, and students are free to direct their criticism even at those things considered fundamental to a discipline.

Thus, while the canon of any discipline or practice - what is reported in explicit classroom texts - represents an important awareness of previous thoughts and findings, over-reliance on it is problematic. The canon becomes outdated, loses relevance, builds up existing harmful power structures, and halts innovation. It often reflects the unsurfaced mental models that Senge warned against - the "deeply ingrained assumptions, generalizations, or even pictures or images that influence how we understand the world and how we take action" [6, p. 8]. In a noncanonical approach, not only is noncanonical knowledge representative of existing actual practices within a social system, but it is representative of the potentially new practices that can come out these systems. While novice students may not be as experienced in actual practices in a given discipline, they are experts in potentially new practices. Thus, a noncanonical approach is inherently innovative. And, in-so-far as learning should include a critical second-loop [7] - whereby a student's questioning of information serves as a feedback loop to change that information - this noncanonical 
knowledge creation is one of the goals of education. With the development of new and shifting canons of knowledge, students become the change agents that uncover and replace faulty mental models with ones that are more valid and just.

Communities of Practice (CoP) are suggested as an ideal framework within which noncanonical knowledge creation can be done [3]. By turning classrooms into an adapted CoP, instructors are situated to move beyond the texts or canons of their disciplines. This occurs as they a) invite unique student contributions to create ideas and knowledge that go beyond existing texts, b) develop trust and community among students that goes beyond simple icebreakers and standard group work, and c) engage consistently in action that recognizes the practical utility of what is learned. The goal is to encourage the creation and discovery of noncanonical knowledge that goes beyond current canonical texts. It is a means of fulfilling the mission of New Librarianship: "To improve society through facilitating knowledge creation in their communities" [1, p. 15]. The goal is for students to begin their careers already equipped with innovative ideas and a recognition of the processes for developing and implementing them. Rather than isolate this as a separate class, a noncanonical approach is offered as a component for every class, irrespective of content. In this way, innovation - and the goal of librarianship and other information/knowledge professions becomes embedded in the curriculum writ large.

\section{Existing instructional modes}

Several pedagogical models have been offered to inspire learning and innovation, and a comprehensive review is beyond the scope of the current paper. However, some are noted in order to identify a common thread. A traditional pedagogical model is the lecture format, though "the inherent defects of the lecture method mean that, on its own, it is rarely adequate" [8, p. 252]. One example of adding to this traditional method is the use of Twitter during a lecture, which has been shown to increase student engagement as it decreased the intimidation of vocal participation [9]. An additional approach that has received significant attention is the flipped classroom [10]. Here, the lecture component is removed as students interact with course materials prior to coming to class, leaving class time for collaborative work. The goal of this approach is active learning, student self-determination and motivation, and a better managed cognitive load - though there is a lack of empirical study into its actual effectiveness [10]. Online education is also receiving increased attention as more and more students are taking courses online [11]. And though the removal of time barriers is beneficial to students, they need additional assistance getting to the goal of increased autonomy in these courses [12]. What bridges all of these models is a desire to meaningfully engage students. The push toward noncanonical knowledge outlined in the current paper offers an additional means of engaging students, while simultaneously shifting the content and practices of entire fields and professions. And, ultimately, "learning is the process of creating knowledge" [13, p. 194]. 
A noncanonical approach is not meant as a replacement for these models, as it is not itself a model. More accurately, it is a new approach. It is proposed as a new way of looking at classrooms that sees them as Complex Adaptive Systems (CAS). As such, they are made up of "living, independent agents ... [who] self-organize and continuously fit themselves, individually and collectively, to ever-changing conditions in their environment" [14, p. 48]. Viewing a classroom this way has several implications for its organization, including a fuller understanding of student agency, a new locus for innovation that comes from students themselves, a recognition of unpredictability and the necessity of failure, and the central role of conversation and unique student contributions. Seeing classrooms as a CAS brings in the importance of Stacey's Control Parameters for such systems - information flow, diversity, and richness of connectivity. There is a critical point for each system at which these parameters lead it to the Edge of Chaos - the point at which innovation and creativity is the greatest [15].

It is also proposed as a new genre for instructional communication that inspires knowledge creation. A genre is "a distinctive and recurring pattern of similarly constrained rhetorical practices" [16, p. 42]. They are "characterized by similar substance and form" and conducted in the "context of socially defined recurrent situations" [17, p. 301]. A noncanonical approach serves as a means of giving shape to existing pedagogical methods rather than replacing them. The classroom is an ideal place for a new genre to develop, because it is already home to several recurring forms of rhetorical practice - i.e. the lecture. Some substance and form elements typical of this new genre include debate, open knowledge sharing, mutual definition, productive inquiry, interdependency, and experimentation.

\section{What is a community of practice?}

CoPs undergird a noncanonical approach as an ideal educational platform that goes beyond existing texts, as knowledge creation is fundamental to a CoP [18]. Wenger suggested that, because CoPs "can preserve histories of learning as living practices, not just books and databases", they are "the ideal context for ensuring that new generations of members are ready to carry a competence into the future" $[19$, p. 251]. CoPs are "groups of people who share a concern, a set of problems, or a passion about a topic, and who deepen their understanding and knowledge of this area by interacting on an ongoing basis" [20, p. 4]. The current paper suggests that classrooms can be CoPs, though CoPs are typically studied in other organizational settings. For instance, CoPs have been noted in virtual communities that combine old and new technologies to create knowledge [18]; in small public research institutes that speed up the research process [21]; and in collective ventures that attempt to increase the affordability of electric cars [22]. What joins individuals together is a common purpose [23], and it is suggested that this purpose is shared among students in a classroom. 
However, the classroom represents a specific type of CoP, as several aspects of it are intentionally designed. They fall under what Saint-Onge and Wallace [24] described as a structured CoP, in which membership is invited, there is formal sponsorship from the larger organization, and objectives are aligned with the larger organization. The existence of a classroom stems from curricular decisions, and students often lack choice in the decision of what a given class is about. Yet, such a designed environment can still be described as a CoP, so long as the design is done "with a light hand, with an appreciation that the idea is to create liveliness, not manufacture a predetermined outcome" [20, p. 64]. This is backed up by "extant literature [that] provides evidence which demonstrates that CoPs can be intentionally deployed which is contrary to the common view that CoPs need to emerge naturally" [25, p. 9].

The value of a CoP within education is that it provides the platform for students to push against disciplinary assumptions while still remaining part of the system. Too often, the discourses of higher education work to silence the critical thought it purports to encourage. This can be seen with information literacy instruction that, through universal standards, makes several assumptions that ignore the multiple contexts that impact the acceptance of information literacy [26]. Part of the movement of information literacy education toward "more human-centered understandings" [26, p. 82] is opening up its very definition to a diverse student population. Yet, higher education must be aware that this opening of the text is an uncomfortable move meant to benefit students. It is not another means by which to control the academic discourse to maintain the assumptions it holds dear: "It is, at the very least, paradoxical to see how collaboration triggered by alienation can be turned into a management tool" [27, p. 533].

Though the lack of predetermined outcomes [20] may seem counterintuitive, it matches the spirit of learning outcomes. Learning outcomes are distinct from objectives, which suggest more specific goals [28]. Though these outcomes may relate to the students or instructors, they also clearly relate to the subject of the class. Yet, these are not offered with precision. Students can utilize the outcome to the ends they choose: "The student is free to apply the required knowledge to [an] ... issue of his/her choice" [28, p. 99].

\section{Using CoPs}

This section will outline the use of CoPs for the development of noncanonical knowledge in classrooms, moving beyond the text. The elements of a $\mathrm{CoP}$ are discussed in terms of what they mean, how they encourage the development of noncanonical knowledge, and what instructors can do to implement them.

The structure of a CoP generally includes a domain, a community, and a practice [20]. This section will define each structural element, outline its impact on the development of a noncanonical knowledge that goes beyond the existing text, and provide practical examples of how each element can be put into practice. Figure 1 


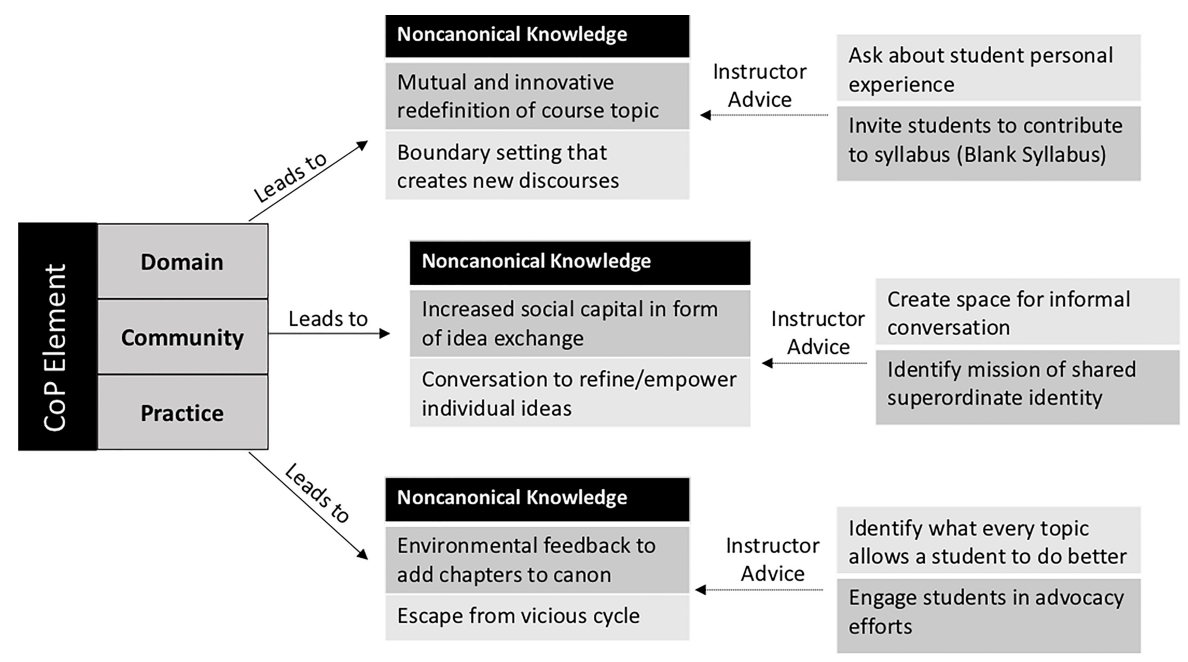

Fig. 1. Using communities of practice for noncanonical knowledge creation in the classroom.

provides a graphic overview of this process. Each element of the $\mathrm{CoP}$ - domain, community, and practice - has specific impacts on the development of noncanonical knowledge creation within the classroom. This noncanonical knowledge comes from mutual redefinition, boundary setting, the transfer of intangible social capital, empowered conversation, environmental feedback, and the escape from a vicious cycle of searching for perfection. For each element, there are also practical ways for instructors to do this in their classrooms.

\subsection{Domain}

This section outlines the first component of a CoP - its domain. The goal of the domain in the context of education is to engage students in pooling their unique insights in the context of questioning existing discourses. They are then in a position to create new discourses that challenge the status quo assumptions of the occupations they wish to enter - turning them into immediate change agents.

The domain defines what the group is about, and its boundaries must be purposefully created by group members. It is the topic of the group and creates the boundaries around what the group is about and what is worth sharing, i.e. is my knowledge applicable to this topic? The domain is how someone knows "what matters to [a] community" and what is "relevant" [20, p. 29-30]. Individuals who are interested in this general topic self-enroll into the group. Yet, defining the domain as a topic is an oversimplification. The domain is a shared interest that represents what the group's expertise is, and it helps establish commitment from membership to the group. The specificities of this domain are created by the members themselves through negotiation, which creates meaning for the group [19]. As they begin discussion, each 
member considers and contributes their own unique experiences and expertise as it relates to the general topic: "As people participate in a community they bring with them their personal histories of norms and prior practices, which may result in conflicts that need to be negotiated and perhaps will never be resolved" [29, p. 2282]. This is necessary so that the members can take ownership of it [19]. This ownership increases commitment to the group.

\subsubsection{Domain and noncanonical knowledge}

There are two elements of this domain - and its development - that lead to noncanonical knowledge creation in the classroom. First, it is important that the domain is mutually defined among students and instructor, rather than defined a priori. Although a broad course topic is proposed, mutual definition of the domain occurs as students are asked to contribute their own unique experiences and knowledge - what only one person knows [30] - to reshape what this topic actually looks like. It is important that this is done intentionally, as there are dynamics "that militate against the discussion of [unique] information" [31, p. 152]. A lack of intentionality here results in an over-contribution of shared information that all students held in common prior to discussion: "Unstructured group discussion is a less-than-optimal means of pooling members' unshared information and why groups often have difficulty accessing the very information that such discussion is intended to elicit" [32, p. 104].

This pooling of ideas not only leads to better decision-making [32], but it respects the human agency and potential of students to go beyond a fallible text. Within the classroom, students tap into the "self-organizing processes that produce complex adaptive systems" [33, p. 672]. And as they pool more and more information, the control parameters of the classroom system are altered to push it closer to the edge of chaos [15] at which point noncanonical knowledge creation is possible. A series of classroom topics mutually defined will extract more of students' uniqueness in an effort to develop noncanonical knowledge that is more representative of this uniqueness.

Second, it is important that students are involved in determining the boundaries around a given domain and membership in that domain, giving them power to change them as they see fit. These boundary markers are similar to discourses in Gee's definition of literacy, which represent identity kits that include the ways of acting, talking, thinking, etc. that mark someone as being part of a particular group [34, p. 7]. Students come to a course with several discourses. Some come from the primary discourse they learned as a child, while other secondary discourses are acquired throughout their lifetime. These secondary discourses are liberating [34], as they allow for the critique of other discourses, enabling students to redefine these membership boundaries. The classroom is where meta-knowledge [34] of these discourses is learned, such that students are able to question the values and beliefs of the professional and academic discourses they are about to enter. By learning what an information/knowledge professional does and what they value, students are able to use their other value systems - or discourses - to question these values. This, to 
Gee, represents a "good combination for successful students and successful social change" [34, p. 13]. Students are recreating the boundary.

Kuhn suggested that education within an accepted paradigm "prepares the student for membership in the particular scientific community with which [they] will later practice" [4, p. 11]. As the student enters actual practice, then, this practice will "seldom evoke overt disagreement over fundamentals" as they are "committed to the same rules and standards for scientific practice" [4, p. 11]. However, rather than come to a discipline or profession having adopted the accepted rules within a predetermined boundary, a noncanonical approach suggests that students come ready to shake things up.

\subsubsection{Advice for instructors}

Noncanonical knowledge creation, then, comes as classrooms are viewed as full of autonomous agents who drive self-emergent change. Instructors can ask students to contribute personal experiences they have with a given class topic, recognizing the pooling value of such contributions. Instructors can legitimize these voices by opening up spaces in the syllabus for these contributions to be codified. For instance, Walsh [35] outlined the Blank Syllabus, in which some required readings are left blank. Students choose a reading and make a case for its inclusion in the syllabus as required reading for all students. As they do this, instructors look for and provide space for the full expression of human potential - something the leaders of most other human systems fail to do. Most systems are "patently oligarchical" [14, p. 51]. Consider, for instance, how individuals are narrowly squeezed into job descriptions in organizations - or racial stereotypes in communities - that determine what leaders think they can offer. Instructors can highlight areas of their respective disciplines that are debated within the field - inviting students into that debate. Not only does this show students the nature of knowledge, but the invitation serves as a recognition of a students' potential. Finally, when instructors give voice to the wide breadth of discourses in the classroom, they provide the space necessary for critique. Students see "how the Discourses [they] have already got relate to those [they] are attempting to acquire, and how the ones [they] are trying to acquire relate to self and society" [34, p. 13]. Essentially, instructors can outline for students the words, values, and beliefs of those in the professions they want to go in. They then ask, are you ok with that?

\subsection{Community}

This section outlines the second component of a $\mathrm{CoP}$ - community. The goal of community in the context of education is for students to develop meaningful relationships that they can draw on for important resources in the creation of relevant and pragmatic knowledge. They can then utilize the power of communication to refine ideas into noncanonical knowledge powerful enough to push against the existing canon of thought and practice in a given area. 
Moving beyond the text requires trust and engagement within the classroom, and community is the social element that creates the foundation for noncanonical knowledge creation to occur. It is the "social fabric of learning" that "fosters interactions and relationships based on mutual respect and trust" [20, p. 28]. Community denotes the ability to have productive conversations in a high-trust environment [24]. This trust requires the sense that one's contributions will be valued. Community addresses personal relationships and an understanding of each other, and it includes removing the barriers to relationship [20]. Yet, effort must be taken to ensure that this barrier removal does not lead to sameness and lack of conflict, as a $\mathrm{CoP}$ is made up of people whose diversity is part of their identify [27]. A CoP is "neither a haven of togetherness nor an island of intimacy insulated from political and social relations" [19, p. 77]. Mutual engagement connects CoP members in ways that go beyond surface-level similarities [19].

\subsubsection{Community and noncanonical knowledge}

There are two elements of community - and its development - that lead to noncanonical knowledge creation in the classroom. First, it is important that this community element focuses on trust and relationship among students - something lacking in higher education [12]. Out of these networks, norms, and trust [36] comes the development and availability of social capital (SC) - "the sum of the actual and potential resources embedded within, available through, and derived from the network of relationships possessed by an individual or social unit" [37, p. 243]. Noncanonical knowledge is, itself, one of these resources. In fact, it was the resource Xerox technicians used to fix machines, as "the technicians depend on each other to fill these gaps" [2, p. 31]. In a similar way, a student is equipped with textbooks and lectures, and is typically viewed as independent. Yet, more complete learning requires the addition of noncanonical knowledge resources that come out of relationship. This SC is embedded within the relationships themselves [38].

This trust requires intentionality, however, as it is all too easy for the exchange of these noncanonical resources to be blocked by in-group mentalities. Social Identity Theory posits that people identify with certain groups that fill them with pride, causing them to view in-group members more favorably than out-group members: "The mere perception of belonging to two distinct groups ... is sufficient to trigger intergroup discrimination favoring the in-group" [39, p. 13]. In a classroom, then, noncanonical knowledge may only be held and exchanged within independent small groups. This severely limits the potential access to - and utilization of - these resources that would be seen within a growing SC network.

Second, it is important that this community element focuses on productive conversations: "The degree to which a culture values effective communications and connectivity between individuals and groups will materially affect the rate and quality of its innovation" [14, p. 55]. It is through conversation that knowledge is created [1]; it comes "through the interactions amongst individuals or between individuals and their environments, rather than by an individual operating alone" [39, p. 15]. This 
is because groups help refine individual ideas: "Together they are scrutinized, discussed, modified and refined" [14, p. 46].

Yet - in the same way that group work requires the contribution of unique information - productive conversation requires productive inquiry (PI). PI comes from the work of John Dewey, and is the process of "actively pursuing a problem ... to seek an answer" [40, p. 62]. It is "a dynamic questioning and validation process that draws out tacit knowledge to give meaning to explicit knowledge" [24, p. 17]. A classroom may have diverse students, but a lack of PI may keep them from benefiting from this diversity due to a tendency to converge into sameness $[19,27]$.

Conversation also enables the creation of noncanonical knowledge in-so-far as it changes the locus of authority and expertise. Rather than view the textbook - and scholars with official peer-reviewed avenues of publication - as the ultimate authority, students begin to see the authoritative nature of what they create. This is a core piece of Habermas' Theory of Communicative Action, as members of a group use conversation to challenge existing power structures, as "mutual understanding [is the] mechanism for coordinating action" [41, p. 330]. Classroom conversation is able to situate knowledge creation within a framework of what works best for students - rather than what would help them get a high grade as they rehash existing information - so long as this conversation is free from "domination and strategic motivations on the part of any participant" [42, p. 85]. And as noncanonical knowledge is created, "authority and tradition ... [lose] their status as ultimate sources of legitimacy" [43, p. 710].

\subsubsection{Advice for instructors}

To benefit from the noncanonical knowledge creation that comes from students engaged in relationship development and conversations, instructors can first provide the space for this to occur. It can be easy to see informal discussion not related to the class topic as a waste of time. Yet, the space for these interactions is the bedrock of knowledge creation - what Nonaka et al. referred to as $b a$ : "The shared context for knowledge creation" [44, p. 8]. It is the physical or virtual place that provides the energy for knowledge creation through interaction. It is the space in which "students and teachers can enter into a fearless communication with each other and allow their respective life experiences to be their primary and most valuable source of growth and maturation" [45, p. 60]. In classrooms where answers are already provided without this space, there is no PI - thus, there is no noncanonical knowledge creation. Through the mere sharing of experiences, the socialization of students creates shared tacit knowledge [46]. As students begin to articulate and express these thoughts, this externalization turns tacit knowledge into explicit knowledge [46].

Instructors can also use what they learn from students to help them identify a superordinate identity to which they all belong. This has been shown to reduce in-group favoritism and increase knowledge sharing in group work [47]. The goal for the community element is the discovery of the common elements of individual stories that brings students under this larger umbrella. Instructors can help students discover and 
devise a mission statement for this larger group to which they all want to contribute. Under this umbrella of a superordinate identity, students will be more likely to trust one another, which is essential for the sharing that undergirds the creation of noncanonical knowledge.

\subsection{Practice}

This section outlines the third component of a $\mathrm{CoP}-$ its practice. The goal of practice in the context of education is for students to continuously connect knowledge to practice - going beyond learning to doing. The experimentation that is part of this process exposes students to failure and the unpredictability that is inherent in all human systems.

Moving beyond the text requires action. Practice is what separates a $\mathrm{CoP}$ from a community of interest. CoPs emphasize the importance of learning by doing, or situated learning [48]. It is only as individuals engage in solving a problem together that they best learn and develop new tools and practices to confront these problems [23]. This echoes the importance of learning by doing in Nonaka and Takeuchi's SECI model [46]. A CoP's practice encompasses anything that can be said to be a part of the living curriculum for that domain - the "concepts, symbols, and analytic methods" used to engage with the domain [20, p. 38]. It is a community's shared set of resources, as well as the activities it engages in to learn and produce new knowledge. In essence, the practice of a $\mathrm{CoP}$ includes a) the activities that members engage in together, b) the ways in which they engage in these activities, and c) the products they actually produce from this engagement. For some domains, the practice is relatively straightforward. In other domains - specifically those areas of "similar problems that are not officially recognized as domains" [20, p. 30] - the definition of a practitioner needs further clarification. The very nature of the $\mathrm{CoP}$ suggests that failure will be part of this practice: "The indigenous production of practice makes communities of practice the locus of creative achievements and the locus of inbred failures" [19, p. 85]. A noted benefit of a CoP is that it can take more risks because they have the backing of an entire community [20, p. 15].

\subsubsection{Practice and noncanonical knowledge}

There are two elements of practice - and its development - that lead to noncanonical knowledge creation in the classroom. First, it is important that this practice element considers what it means to be a practitioner - more than merely a learner in the given domain. This is a rejection of the well-known claim by Francis Bacon that "knowledge itself is power" [49, p. 71]. An individual can have knowledge about something, but not do anything with that knowledge. Consider, for instance, the smoker who continues to smoke in spite of the knowledge that smoking leads to cancer. Knowledge exists merely as a tool for potential use. Knowledge should not be the goal of the classroom; rather, the goal should be action: "The essence of wisdom ... lies not in what is known but rather in the manner in which that knowledge is held 
and in how that knowledge is put to use" [50, p. 187]. Cook and Brown described this as knowing: "We use the term 'knowing' to refer to the epistemological dimension of action itself" [40, p. 387]. This is related to models of experiential learning that suggest that "knowledge is created through the transformation of experience" [51, p. 41]. Recent research on experiential learning has shown that it increases a student's emotional engagement [52]. This also provides additional information in the form of environmental feedback which can be used to develop noncanonical knowledge.

Second, it is important that this practice element includes risk-taking and failure. A fundamental component of noncanonical knowledge creation is failure. Stacey [15] suggested that social systems operate within rugged landscapes that are made up of several peaks and valleys. The peak represents a high level of fitness between the system and its environment. Often, a system reaches a peak only to find out that it is a mere foothill hiding a larger peak. Increased fit, then, requires "stumbles and rolls downhill" [15, p. 83]. Entering the workforce having never failed will put students in a position to assume that perfection should be expected. Stacey [15] called this a vicious cycle of looking for savior recipes that guarantee success. This will lead to frustration and futile searches for additional savior recipes. Breaking out of this cycle requires a recognition of the complexity of any living social system, which is never "so long as it is alive, in a state of chemical and thermodynamic equilibrium" [53, p. 39]. Students must acknowledge the lack of predictability, and accept the failures associated with ambiguity. Instead of asking how they can design for success, then, students ask how they can make sense of complexity [15]. This question allows them to see the rugged nature of the landscape, better equipping them to navigate it.

\subsubsection{Advice for instructors}

The practice of a CoP suggests that, for every class session, instructors can consider what the course material helps a student do better. They can then provide space for students to engage in doing. This is commonplace in many STEM courses with lab requirements. Yet, this action element can extend to other courses without a clear lab component, e.g. an information literacy course. As part of a discussion of political information literacy, for example, students could be tasked with contacting a governmental representative. As part of a discussion of health information literacy, students could also be tasked with developing and implementing an advocacy campaign aimed at increased local awareness of healthy eating. These actions can positively impact the lives of students themselves. Noting the lack of agency for students from underrepresented groups in education, Bland and Atweh [54] outlined an approach in which students acted as the primary researchers in participatory action research (PAR) aimed at uncovering and removing educational barriers.

Instructors can also model the experimentation process for their students, trying different teaching techniques throughout the semester that they are not completely sure will work. This also brings in PI - noted earlier - as practice includes how students engage with course material. Instructors can work to create a culture in which PI becomes commonplace. Freeburg [55] found that the development of this 
Table 1

Outcomes and measurements for success in noncanonical knowledge creation

\begin{tabular}{|c|c|}
\hline Actionable outcome & Measurement \\
\hline $\begin{array}{l}\text { Criticize the practices of existing } \\
\text { professions, the content of existing } \\
\text { texts, and arguments made by the } \\
\text { professor. }\end{array}$ & $\begin{array}{l}\text { Instructor will document the number of substantive student dis- } \\
\text { agreements or critiques - done either in class or through email. } \\
\text { Students will be presented with this and asked to reflect on the } \\
\text { value of criticism. }\end{array}$ \\
\hline $\begin{array}{l}\text { Create new ideas - as a class - } \\
\text { about the course topic not ex- } \\
\text { pressed in the readings or lectures. }\end{array}$ & $\begin{array}{l}\text { Students will keep a journal of new ideas they create as a class } \\
\text { throughout the course. Students will get together to discuss these. } \\
\text { Each student will then send a copy of these ideas, along with a } \\
\text { reflection on the value and quality of these ideas. }\end{array}$ \\
\hline $\begin{array}{l}\text { Contribute unique knowledge with } \\
\text { other students. }\end{array}$ & $\begin{array}{l}\text { Students will keep a journal of the unique contributions they offer } \\
\text { throughout the course. They will send this to the instructor along } \\
\text { with a reflection on how these were unique, the impact they made } \\
\text { on group discussion, and how they will do this moving forward. }\end{array}$ \\
\hline $\begin{array}{l}\text { Analyze the lessons learned from } \\
\text { failure in one classroom task. }\end{array}$ & $\begin{array}{l}\text { Each student is expected to fail in some aspect of the course. Be- } \\
\text { cause it is unlikely that students will risk getting a bad grade, these } \\
\text { will be restricted to non-graded aspects of the course, e.g. talking } \\
\text { before you've formulated an idea, making a bad suggestion for } \\
\text { group work. A description of the failure and lessons learned will } \\
\text { be submitted to the instructor. }\end{array}$ \\
\hline
\end{tabular}

culture requires a loosened attachment to beliefs about information, a recognition of fallibility in information, a focus on the need for information to be relevant, comfort with debate, and acknowledgement of diversity. These all point to an environment that allows students to go beyond the text.

This moves the classroom from a place of learning to a place of doing. And, inso-far as it interferes with a student's existing beliefs and assumptions, this will not always come naturally. As instructors are learning more about their students, they can identify what Lewin [56] referred to as a force field with driving and restraining forces to change. Getting students to the point of knowing and risk-raking - what may be a new behavior for them - requires breaking through barriers. This can be done through an "emotional stir-up" [56, p. 34], an increased awareness of the cost of not acting [57], the creation of psychological safety to overcome learning anxieties [58], or the customization of course material to the "unique needs, beliefs, or characteristics of individuals" [59, p. 1567].

\section{Success}

The general outcome of the proposed model is engaging students in moving beyond the text as they create noncanonical knowledge. Yet, how is this measured? Every class syllabus has a list of learning outcomes that represent what students are expected to learn and do. The three primary goals laid out in the current paper offer a starting point for shifting the language and intent of more specific learning outcomes. Rather than provide universal learning outcomes, Table 1 provides measurable actions students should be able to undertake according to a noncanonical approach. 
This includes the actual creation of new ideas, as well as several actions likely to lead to the creation of new ideas, e.g. criticism, unique contribution, and experimentation. It also outlines ways to measure success. All outcomes are easily recognizable by both student and instructor, allowing for easy documentation throughout the course. A reflection on the utility of each provides an additional measure of what the student learned.

These can be adapted by instructors into learning outcomes for their courses that incorporate the elements of a noncanonical approach. Note that students are allowed, in this table, to provide evidence of each outcome in class discussion or through email. However, any emails will be shared with the rest of the class in order to benefit from information pooling.

\section{Conclusion}

The current paper outlined a noncanonical approach for classroom instruction that helps students move beyond existing explicit texts as they create and discover noncanonical knowledge. The expanded research of CoPs in virtual environments [18] suggests that a noncanonical approach could also be used in online courses. Noncanonical knowledge creation is essential to any discipline, yet it has a special place in LIS which - long a discipline of the text - is itself moving beyond this as it focuses on knowledge creation [1]. More than mere pedagogical techniques, this is an approach to how instructors view classrooms and the students within them. Instructors recognize and trust the unique insights of students as they bring them into the practice of knowledge creation - a practice central to a knowledge economy. And the CoP provides a practical means of engaging with the stated goals. These goals include the creation of noncanonical knowledge as students pool their insights and question the status quo; utilization of the power of meaningful relationships and conversations to refine this non-textual knowledge; and engagement in actual experimentation and action related to these ideas. Success in the stated learning outcomes puts students in a position to lead and become true change agents. This can be uncomfortable for all involved, yet it is the only means by which social systems adapt and survive.

\section{References}

[1] Lankes RD. The Atlas of New Librarianship. Cambridge, Mass: The MIT Press; 2011.

[2] Orr JE. Talking About Machines: An Ethnography of a Modern Job. Ithaca, NY: ILR Press; 1996.

[3] Brown SJ, Duguid P. Organizational learning and communities of practice: Toward a unified view of working learning and innovation. Organ Sci 1991; 2(1): 40-57.

[4] Kuhn TS. The structure of scientific revolutions. In: International Encyclopedia of Unified Science, Neurath O. editor. Chicago, IL: The University of Chicago; 1970. (Original work published 1962).

[5] O'Hear A. An Introduction to The Philosophy of Science. New York, NY: Oxford University Press; 1989. 
[6] Senge PM. The Fifth Discipline: The Art and Practice of The Learning Organization. New York, NY: Doubleday/Currency; 1990.

[7] Argyris C. Double loop learning in organizations. Harv Bus Rev [Internet] 1977; 55(5): 115-25. Available from: http://www.westernsnowandice.com/09-Presos/DoubleLoop.pdf.

[8] Bligh DA. What's The Use of Lectures? San Francisco, CA: Jossey-Bass Publishers; 2000.

[9] Tiernan P. The influence of Twitter on lecture engagement and discussion. Educ and Inf Tech 2011; (78). Available from: http://doras.dcu.ie/17805/.

[10] Abeysekera L, Dawson P. Motivation and cognitive load in the flipped classroom: Definition, rationale and a call for research. High Educ Res Dev 2015; 34(1): 1-14.

[11] Seaman JE, Allen IE, Seaman J. Grade increase: Tracking distance education in the United States. Babson Survey Research Group; 2018. Available from http://onlinelearningsurvey.com/reports/ gradeincrease.pdf.

[12] Serdyukov P, Hill R. Flying with clipped wings: Are students independent in online college classes? J Res Innov Teach 2013; 6(1): 54-67.

[13] Kolb DA, Kolb AY. Learning styles and learning spaces: Enhancing experiential learning in higher education. Manag Learn 2005; 4(2): 193-212.

[14] McElroy MW. The new knowledge management. J KMCI 2000; 1(1): 43-67.

[15] Stacey R. Complexity and Creativity in Organizations. San Francisco, CA: Berrett-Koehler Publishers; 1996.

[16] Simons H. Genre-alizing about rhetoric: A scientific approach. In: Form and Genre: Shaping Rhetorical Action. Campbell KK, Jameison KH. editors. Falls Church, VA: Speech Communication Association. p. 33-50.

[17] Yates J, Orlikowski WJ. Genres of organizational communication: A structurational approach to studying communication and media. Acad Manag Rev 1992; 17(2): 299-326.

[18] Schiavone F, Borzillo S. Creating technological knowledge in vintage communities of practice. J Knowl Manag [Internet] 2014; 18(5): 991-1003. Available from: http://www.emeraldinsight.com/ doi/10.1108/JKM-06-2014-0251.

[19] Wenger E. Communities of Practice: Learning, Meaning, and Identity. Cambridge, UK: Cambridge University Press; 1998.

[20] Wenger E, McDermott R, Snyder WM. Cultivating Communities of Practice: A Guide to Managing Knowledge. Boston, MA: Harvard Business School Press; 2002.

[21] Pavlin S. Community of practice in a small research institute. J Knowl Manag [Internet] 2006; 10(4): 136-44. Available from: http://www.emeraldinsight.com/doi/10.1108/13673270610679426.

[22] Pohjola I, Puusa A. Group dynamics and the role of ICT in the life cycle analysis of community of practice-based product development: A case study. J Knowl Manag [Internet] 2016; 20(3): 465-83. Available from: http://www.emeraldinsight.com/doi/10.1108/JKM-06-2015-0227.

[23] Davenport E, Hall H. Organizational knowledge and communities of practice. Ann Rev of Inf Sci and Tech 2002; 36: 171-227.

[24] Saint-Onge H, Wallace D. Leveraging Communities of Practice for Strategic Advantage. London and New York: Butterworth Heinemann; 2003.

[25] Agrawal A, Joshi KD. A review of community of practice in organizations: Key findings and emerging themes. In: 44th Hawaii Int Conf Syst Sci 2011; 1-10.

[26] Elmborg J. Critical information literacy: Implications for instructional practice. J Acad Librariansh 2006; 32(2): 192-9.

[27] Cox A. What are communities of practice? A comparative review of four seminal works. J Inf Sci 2005; 31(6): 527-40.

[28] Allan J. Learning outcomes in higher education. Stud High Educ [Internet] 1996; 21(1): 93-108. Available from: http://www.tandfonline.com/doi/abs/10.1080/03075079612331381487.

[29] Dessne K, Bystrom K. Imitating CoPs: Imposing formality on informality. J Assoc Inf Sci Technol 2015; 66(11): 2277-84.

[30] Hinsz VB, Tindale RS, Vollrath DA. The emerging conceptualization of groups as information processors. Psychol Bull [Internet] 1997; 121(1): 43-64. Available from: http://doi.apa.org/getdoi. cfm?doi=10.1037/0033-2909.121.1.43 
[31] Larson JR, Sargis EG, Elstein AS, Schwartz A. Holding shared versus unshared information: its impact on perceived member influence in decision-making groups. Basic Appl Soc Psych 2002; 24(2): 145-55.

[32] Larson JR, Christensen C, Franz TM, Abbott AS. Diagnosing groups: The pooling, management, and impact of shared and unshared case information in team-based medical decision making. J Pers Soc Psychol 1998; 75(1): 93-108.

[33] Espejo R. The footprint of complexity: The embodiment of social systems. Kybernetes [Internet] 2004 Mar; 33(3/4): 671-700. Available from: https://www.emeraldinsight.com/doi/10.1108/ 03684920410523643.

[34] Gee JP. Literacy, discourse, and linguistics: Introduction. J Educ 1989; 171(1): 5-17.

[35] Walsh C. The blank syllabus. n.d. Retrieved from: https://static1.squarespace.com/static/52029e7 9e4b03a4dabcd55bc/t/5210360fe4b09a53f3443387/1376794127995/Walsh--the+Blank+Syllabus. pdf.

[36] Putnam RD. Tuning in, tuning out: The strange disappearance of social capital in America. PS Polit Sci Polit [Internet] 1995; 28(4): 664. Available from: http://www.jstor.org/stable/420517?origin $=$ crossref.

[37] Nahapiet J, Ghoshal S. Social capital, intellectual capital, and the organizational advantage. Acad Manag Rev 1998; 23(2): 242-266.

[38] Coleman J. Social capital in the creation of human capital. Knowl Soc Cap [Internet] 2000; 94(1988): 17-41. Available from: http://linkinghub.elsevier.com/retrieve/pii/B9780750672221 500052.

[39] Tajfel H, Turner JC. The social identity theory of intergroup behavior. In: Psychology of Intergroup Relations. Worchel S, Austin WG. editors. $2^{\text {nd }}$ edition. Chicago, IL: Nelson-Hall; 1986. p. 7-24.

[40] Cook SDN, Brown JS. Bridging epistemologies: The generative dance between organizational knowledge and organizational knowing. Organ Sci [Internet] 1999; 10(4): 381-400. Available from: http://pubsonline.informs.org/doi/abs/10.1287/orsc.10.4.381.

[41] Habermas J. The Theory of Communicative Action, Vol. 2. Lifeworld and System: A Critique of Functionalist Reason. (McCarthy T. translator). Boston: Beacon Press; 1987.

[42] Schlosberg D. Environmental Justice and the New Pluralism: The Challenge of Difference for Environmentalism. Oxford: Oxford University Press; 1999.

[43] Wellmer A. On critical theory. Soc Research: An Intern Quart 2014; 81(3): 705-733.

[44] Nonaka I, Toyama R, Konno N. SECI, ba and leadership: A unified model of dynamic knowledge creation. Long Range Plann 2000; 33(1): 5-34.

[45] Nouwen H. Reaching Out. New York: Doubleday; 1975.

[46] Nonaka I, Takeuchi H. The knowledge creating company: How Japanese companies create the dynamics of innovation. New York, NY: Oxford University Press; 1995.

[47] Kane AA, Argote L, Levine JM. Knowledge transfer between groups via personnel rotation: Effects of social identity and knowledge quality. Organ Behav Hum Decis Process 2005; 96(1): 56-71.

[48] Lave J, Wenger E. Situated learning: Legitimate peripheral participation. Cambridge, UK: Cambridge University Press; 1991.

[49] Bacon F. Meditations sacrae and human philosophy. Whitefish, MT: Kessinger Publishing; 1996. (Originally published 1597).

[50] Meacham JA. The loss of wisdom. In: Wisdom: Its Nature, Origins, and Development. Sternberg RJ. editor. Cambridge, UK: Cambridge University Press; 1990. p. 181-211.

[51] Kolb DA. Experiential learning: Experience as the source of learning and development. Upper Saddle River, NJ: Prentice Hall; 1984.

[52] Finch D, Peacock M, Lazdowski D, Hwang M. Managing emotions: A case study exploring the relationship between experiential learning, emotions, and student performance. Int J Manag Educ 2015; 13(1): 23-36.

[53] von Bertalanffy L. General System Theory: Foundations, Development, Applications. New York, NY: George Braziller; 1968.

[54] Bland D, Atweh B. Students as researchers: Engaging students' voices in PAR. Educational Action Research 2007; 15(3): 337-349. 
[55] Freeburg D. Acceptance of knowledge management concepts in religious organizations: The impacts of information and willful disengagement from productive inquiry. Proc Assoc Inf Sci Technol 2015; 52(1): 1-10.

[56] Lewin K. Frontiers in group dynamics. Human Relations [Internet] 1947; 1: 5-41. Available from: http://journals.sagepub.com/doi/10.1177/001872674700100103.

[57] Caplan B. Rational ignorance versus rational irrationality. Kyklos 2001; 54(1): 3-26.

[58] Schein EH. Kurt Lewin's change theory in the field and in the classroom: Notes toward a model of managed learning. Syst Pract [Internet] 1996; 9(1): 27-47. Available from: http://www.machonadler.co.il/readers/reader16.pdf.

[59] Cortese J, Lustria MLA. Can tailoring increase elaboration of health messages delivered via an adaptive educational site on adolescent sexual health and decision making? J of the Amer Soc for Infor Sci and Tech 2012; 63(8): 1567-1580. 